\title{
O crime organizado em perspectiva mundial
}

ALBANESE, J. S.; DAS, D. K.; VERMA, A. Organized Crime: World Perspectives. New Jersey: Prentice Hall, 2003.

\section{Resumo}

A construção da criminalidade organizada como objeto sociológico constitui um desafio para os cientistas sociais dedicados ao estudo desse tema. Entre os percalços para a conformação do crime organizado como problema sociológico está a sua própria conceituação, que permanece polêmica desde o século XIX. O Livro "Organized Crime: world perspectives" de Jay Albanese, Dilip Das e Arvind Verma, publicado em 2003 pela Editora Prentice Hall, é uma oportuna referência para quem deseja conhecer o crime organizado e suas características nos diversos continentes. Trata-se de uma coletânea de artigos resultante do "Third International Police Executive Symposium" realizado em 1996, no Japão, que reúne autores representantes de dezenove países cobrindo os cinco continentes, os quais analisam a criminalidade organizada em seus respectivos países. A grande contribuição dessa obra é oferecer uma proposta conceitual em seu capítulo introdutório e apontar, com base nas realidades identificadas, os desafios para o futuro.

Palavras-chave: Sociologia da criminalidade. Crime e sociedade.

\footnotetext{
* Universidade Federal do Rio Grande do Sul (UFRGS), Porto Alegre, Rio Grande do Sul, Brasil.
} 


\section{Organized Crime in a World Perspective}

\section{Abstract}

The constitution of the organized crime as a sociological object comprises a major challenge for social scientists devoted to investigate this issue. Among the hindrances to the formulation of organized crime as a sociological problem lies its own conceptualization that remains controversial since the $19^{\text {th }}$ century. The book "Organized Crime: world perspectives" edited by Jay Albanese, Dilip Das and Arvind Verma and published in 2003 by Prentice Hall is an opportune reference for those who seek to know about the organized crime and its characteristics in the distinct world regions. The book is comprised by a collection of articles that resulted from the "Third International Police Executive Symposium" that took place in 1996, in Japan. The authors represent 19 countries from all world regions, and they analyze the organized crime in their respective countries. The major contributions of this work are the conceptual framework proposed in its introduction and the fact of pointing out the future challenges identified from the analysis of the national contexts.

Keywords: Crime sociology. Crime and society.

Uma das primeiras dificuldades para o cientista social que estuda a criminalidade organizada é a sua construção enquanto objeto sociológico e categoria analítica.

Para certos criminólogos críticos, o conceito de crime organizado funciona como discurso que encobre a incapacidade política dos governos de resolverem problemas sociais, e principalmente, de enfrentarem o modelo econômico excludente. Desta forma, a ineficácia governamental seria compensada pela propalada "eficiência" em combater a criminalidade organizada e punir indivíduos e grupos sociais nela implicados.

Todavia, na área da segurança pública e da justiça criminal, o crime organizado é tido como realidade concreta a reprimir (especialmente o tráfico de drogas do varejo), pois, além de ilegal, é identificado como fator explicativo do crescimento das práticas violentas em certos espaços 
sociais. Da estratégia punitiva focalizada resulta o aumento crescente dos presos envolvidos com o tráfico de drogas.

Entrementes, no Brasil, o tema emergiu no discurso acadêmico na década de 1980, quando o tráfico de drogas tornou-se um problema social, com a chegada da cocaína ao varejo, passando a ser comercializada em larga escala e a baixos preços no País, seguindo as novas rotas internacionais de drogas. Em 2007 é publicado o Dossiê Crime Organizado no Brasil (Estudos Avançados, 2007), com o objetivo de ampliar o conhecimento do fenômeno: seus movimentos, múltiplas ações e causas principais.

Entre os percalços para a conformação do crime organizado como problema sociológico está a sua própria conceituação, que permanece polêmica desde o século XIX. Até hoje inexiste uma definição apropriada que esclareça as características organizacionais, a gama de atividades desenvolvidas, ou o perfil dos membros. Uma das razões para essa insuficiente delimitação analítica é a própria natureza do fenômeno: oculto no interior do mundo criminal e avesso a qualquer evidência empírica. Em geral, as estatísticas policiais não contabilizam especificamente o crime organizado; quando o fazem, cobrem apenas aspectos restritos do fenômeno, que se referem mais à atuação policial do que ao próprio fato (ações como blitzes, batidas em áreas previamente selecionadas, dentre outras).

Neste aspecto, pode-se questionar qual é a unidade básica do crime organizado: uma gama de atividades ilegais ou um conjunto de grupos criminosos que estariam como que "organizando" o crime?

O Livro Organized Crime: world perspectives de Jay Albanese, Dilip Das e Arvind Verma ${ }^{1}$, publicado em 2003 pela Editora Prentice Hall, é uma oportuna referência para quem deseja conhecer o crime organizado e suas características nos diversos continentes. Ele reúne artigos de parti-

\footnotetext{
${ }^{1}$ Jay S. Albanese é professor e diretor do Departamento de Justiça Criminal da Virginia Commonwealth University (Richmond, USA); Dilip K. Das é professor no Departamento de Sociologia/Justiça Criminal da State University of New York (Plattsburgh, USA); Arvind Verma é professor assistente no Departamento de Justiça Criminal da Indiana University (Bloomington, USA).
} 
cipantes do Third International Police Executive Symposium, ocorrido em Yokohama/Japão, de 28 de novembro a 01 de dezembro de 1996, onde estiveram presentes representantes de dezenove países para debater sobre: a) o conceito de crime organizado, b) a sua natureza e extensão, c) os métodos e medidas utilizados para enfrentá-lo, e d) a avaliação comparativa das medidas adotadas em cada país.

Entre os participantes do Simpósio estavam: professores e pesquisadores universitários do campo da Justiça Criminal, cientistas sociais, diretores de centros de pesquisa, criminólogos, autoridades policiais, analistas de inteligência, representantes ministeriais e cientistas forenses.

Com 482 páginas, o livro inicia com uma introdução conceitual sobre o crime organizado, seguida de seis partes referentes aos continentes (América do Norte, Europa, Ásia, América do Sul, Austrália, África), intermeadas por capítulos correspondentes a dezenove países² ${ }^{2}$, escritos pelos respectivos representantes. Após a exposição das várias realidades nacionais, um dos autores, Jay Albanese, finaliza com uma conclusão intitulada "Desafios para o futuro". Os capítulos relativos aos países apresentam os seguintes itens: a) Introdução, b) Natureza e extensão do crime organizado, c) Medidas, incluindo legislação para combater o crime organizado, d) Avaliação comparativa dos métodos e medidas de enfrentamento do crime organizado e e) Conclusão.

\section{Delimitação conceitual e principais características nacionais e internacionais do crime organizado}

Na introdução - A framework for understanding - Albanese e Das destacam os fatores condicionantes do crime organizado em cada país,

\footnotetext{
${ }^{2}$ Estados Unidos, Canadá, Itália, Países Baixos, Polônia e Europa Oriental, Rússia, Eslovênia, Áustria, Índia, Japão, China, Colômbia, Argentina, Austrália, Nova Zelândia, África do Sul, Tunísia, Zâmbia e Zimbabwe.
} 
tais como: localização geográfica, circunstâncias econômicas, sociais e políticas, história e cultura nacional.

Em alguns países, o crime organizado está prescrito nas leis penais, em outros, não ${ }^{3}$. Embora não exista uma definição específica sobre crime organizado, em geral as categorizações existentes baseiam-se ou na estrutura do grupo criminoso (independente do tipo de ações, como nos Estados Unidos e Alemanha) ou no tipo de atividade (Holanda, Polônia, Eslovênia). Outra importante diferença entre os países é quanto ao grau de sofisticação das organizações: em alguns casos, elas são definidas como burocráticas (grandes grupos que existem há bastante tempo, possuem hierarquia, são chamados de sindicatos; por exemplo, "Cosa Nostra" ou "Yakuza"); enquanto que, em outros países, o crime organizado abrange grupos menos formais ou gangues que surgem em torno de um produto ou oportunidade ilegal, denotando menor organização. A definição utilizada em cada país vai determinar que tipo de atividades, problemas ou situações farão parte do crime organizado.

O sociólogo canadense Daniel Koenig, citando Jean-Paul Brodeur $(1996)^{4}$, ressalta que é mais adequado falar de associações de criminosos organizando o crime do que associações de crime organizado. Segundo Koenig, Brodeur

[...] prefere o conceito de organizando o crime do que de crime organizado, pois considera as empresas criminais muito mais fluídas do que burocráticas, constantemente evoluindo, adaptando-se e organizando não apenas as suas próprias atividades, mas também as de outros grupos, através das alianças e relações (Koenig, 2003, p. 49, tradução nossa).

\footnotetext{
${ }^{3}$ No Brasil, o artigo 288 do Código Penal prescreve o crime de quadrilha ou bando: Associarem-se mais de três pessoas, em quadrilha ou bando, para o fim de cometer crimes; Pena - reclusão, de um a três anos; Parágrafo único - A pena aplica-se em dobro se a quadrilha ou bando é armado.

${ }^{4}$ BRODEUR, Jean-Paul. Organized Crime: trends in the literature. Paper presented at the Forum on Organized Crime. Ottawa, 1996, September 27-28, apud KOENING, 2003.
} 
Uma definição referida em capítulos do livro é a da International Criminal Police Organization (INTERPOL):

[crime organizado] envolve um grupo de duas ou mais pessoas, cada uma com uma tarefa específica para desempenhar, e que faz uso de estruturas ligadas a empresas, bem como da violência ou de outros meios de intimidação, e exerce influência sobre políticos, a mídia, o governo, as autoridades da justiça criminal ou sobre a economia. [...] qualquer empresa ou grupo de pessoas engajadas em atividade ilegal continuada que tem como seu propósito primeiro a geração de lucros, independente das fronteiras nacionais. [...] Empresa ou grupo de pessoas inclui qualquer associação de criminosos, seja trabalhando em organizações, tais como grandes corporações com regras internas e hierarquias estabelecidas, ou operando juntos em torno de um propósito comum (definição da INTERPOL citada por Plywaczewski, 2003, p. 128, tradução nossa).

As várias perspectivas nacionais apresentadas convergem para as seguintes características comuns (Albanese; Das, 2003, p. 6):

a) Atividades criminais são planejadas com o propósito de lucratividade.

b) Existe uma conspiração ou empresa que é baseada em relações sociais, étnicas ou em negócios pré-existentes, ou ainda em torno de um produto ou oportunidade ilegal.

c) Intimidação, ameaça e violência são usadas para assumir e manter a oportunidade ilícita diante de grupos concorrentes.

d) A corrupção (suborno e extorsão) é frequentemente utilizada para garantir a imunidade diante da interferência governamental e da justiça criminal.

e) Os grupos organizados possuem extrema adaptabilidade para lidar com as mudanças no fornecimento, na demanda, na competição com outros grupos, ou na efetividade da aplicação da lei. Para tanto, movem-se geograficamente, trocam de produto ilícito, procuram novos parceiros, ou 
tomam outras medidas para assegurar a lucratividade e o nível de sucesso em escapar dos agentes de execução criminal. Assim, se as leis de drogas tornam-se mais severas e o risco de apreensão aumenta substancialmente em alguma jurisdição, é razoável acreditar que os grupos de crime organizado irão se deslocar para outros mercados ou produtos ilícitos, tais como: tráfico de seres humanos, fraude, roubo ou jogos ilegais.

f) Existência de conexão entre criminosos em nível regional, nacional ou internacional.

De certa forma, é mais fácil descrever as atividades do crime organizado do que defini-lo. Elas podem envolver qualquer produto ou serviço que produza lucro (Albanese; Das, 2003, p. 7) e abrangem nos dezenove países citados: tráfico de drogas; fraudes financeiras; falsificação de dinheiro ou documentos públicos; extorsão (de proteção ou dinheiro); sequestro; jogo ilegal; tráfico de álcool, de tabaco ou de armas de fogo; tráfico de pessoas, de partes do corpo humano, de espécies ameaçadas de extinção; roubo de diamantes, de ouro ou de pedras preciosas; roubo, comércio ilegal e contrabando de antiguidades e de objetos de arte; roubo de veículos; prostituição internacional; imigração ilegal; exportação ilegal de refugos e lixo; crimes de informática; agiotagem; terrorismo; contrabando de materiais nucleares; corrupção e suborno de agentes públicos; crimes políticos; evasão fiscal; e lavagem de dinheiro.

A lavagem de dinheiro - o investimento dos proventos ilícitos em bancos e outros negócios lícitos - é considerada "o sustentáculo econômico do crime organizado" (Ryan, 1995 apud Albanese; Das, 2003, p. 7) possibilitando ocultar a verdadeira fonte do dinheiro e fornecendo uma fachada legítima ao grupo.

${ }^{5}$ RYAN, Patrick J. Organized Crime. Santa Barbara: ABC-CLIO, 1995, apud ALBANESE; DAS, 2003, p. 7. 
Outro aspecto mundialmente reconhecido como essencial à sobrevivência e o sucesso do crime organizado são as relações estabelecidas com organizações governamentais e autoridades judiciais e policiais. Agentes públicos corruptos abusam de sua posição e poder para obter benefício pessoal, e certas empresas privadas utilizam sua influência para obter vantagem ilícita similar. A convivência do crime organizado com o sistema político atende a dois propósitos:

a) $\mathrm{O}$ crime organizado usa sua influência para cometer suborno, extorsão e corrupção, a fim de garantir imunidade diante da justiça criminal, evitando apreensão e perseguição. Há também a infiltração de criminosos nos aparelhos estatais.

b) Oficiais do governo utilizam a sua posição para roubar propriedades públicas, enriquecer-se ou extrair pagamentos ilícitos de companhias privadas que negociam com o governo.

A simbiótica relação entre o crime organizado e o governo frequentemente envolve o mau uso do poder e da influência de ambos os lados. Raramente o governo figura como uma vítima contrariada. Mais frequentemente, os agentes governamentais dispõem-se a aceitar ou mesmo solicitam pagamentos corruptos do crime organizado (Albanese, Das, 2003, p. 9, tradução nossa).

Nestas linkagens, as tarefas são divididas:

As pessoas de negócios providenciam o capital, pagam pelos custos operacionais e canalizam os lucros para dentro de negócios legítimos. Os burocratas participam com o uso indevido de sua autoridade para providenciar decisões favoráveis aos gangsters organizados, ao neutralizarem ou debilitarem os agentes oficiais que podem impor perigo à empresa criminal, e tomam uma parte do lucro na forma de subornos. Os políticos, cujo maior motivo permanece a conquista de poder, agem como padrinhos, asseguram que a atenção das atividades criminais seja desviada e que 
aqueles que são apanhados sejam tratados indulgentemente pelo Estado. Os resultados dessa potente combinação são letais: o Estado fica comprometido, as agências oficiais são desmoralizadas e se tornam ineficazes, e o erário público é saqueado em imensas somas de dinheiro (Verma; Tiwari, 2003, p. 243, tradução nossa).

Muitas associações criminosas possuem alto grau de adaptabilidade e de sucesso, que é garantido pela seleção estrita do seu staff, pela disciplina rígida de trabalho e pelo foco nos fins lucrativos. Entrevistas com representantes do crime organizado russo (químicos, programadores, economistas, advogados) evidenciaram as múltiplas habilidades profissionais. Além disso, as organizações aspiram monopolizar certa atividade ou território.

Quando os líderes das organizações são presos, eles invariavelmente continuam comandando as atividades criminais de dentro da prisão. Ademais, os membros presos recebem auxílio e assistência (advogados, ajuda aos familiares, etc.).

As razões para o crescimento do crime organizado são várias; por exemplo, a impunidade e a ineficácia da justiça criminal em coibir os crimes de elite, focando mais os crimes praticados por grupos desfavorecidos social e economicamente; o encurtamento da distância (espacial, social, cultural) entre os países, decorrente do fim da Guerra Fria e da globalização; a transnacionalização das organizações criminosas e a crescente demanda nas sociedades pelos produtos e serviços providos pelos grupos criminosos.

[...] o crime organizado providencia produtos e serviços que têm frequentemente grande demanda a despeito das proibições legais. O fato de ele ocorrer em todas as sociedades por grupos de todos os tipos comprova que o mesmo não é estranho e não é uma conspiração contra o tecido social. Ele é, de fato, grande parte deste tecido. (Potter, 1994 apud Albanese; Das, 2003, p. 15, tradução nossa) $)^{6}$.

\footnotetext{
${ }^{6}$ POTTER, Gary W. Criminal Organizations: Vice, Racketeering and Politics in an American City. Prospect heights, IL: Waveland Press, 1994, apud ALBANESE; DAS, 2003, p. 15.
} 
Conforme comenta o representante da Itália no terceiro capítulo do livro:

A sociedade atual produz mais criminalidade organizada devido a algumas de suas principais características. A globalização do capitalismo aumentou a distância entre nações subdesenvolvidas e desenvolvidas, e entre grupos sociais. A monetarização da economia e liberalização da circulação de capitais abriu muitas possiblidades para a lavagem de capitais ilegais. A proibição das drogas tornou os traficantes mais ricos em toda a sua história. O entrelaçamento de economias legais e ilegais, bem como de organizações criminosas e outras instituições sociais, fortaleceu as empresas criminosas. Drogas e lavagem de dinheiro são os tipos mais conhecidos das atividades criminais atuais, mas a mais devastadora é a conexão entre políticos e crime (Santino, 2003, p. 83, tradução nossa).

Umberto Santino acrescenta as facilidades do sistema financeiro internacional para o desenvolvimento do crime organizado:

O sistema financeiro internacional é notoriamente opaco devido ao segredo bancário, paraísos fiscais e inovações financeiras (consistindo de novas formas de coletar capital e outros procedimentos) que favorecem a simbiose entre o capital legal e ilegal. A liberalização da circulação de capital e a criação de vastos mercados transnacionais (Comunidade Econômica Europeia ou Norte-americana, NAFTA) demolem fronteiras, abolem controles e favorecem a circulação de todos os tipos de capital, incluindo dinheiro ilegal. Medidas contra a lavagem de dinheiro são fracas e ineficazes, se comparadas com a presença de grandes transações (Santino, 2003, p. 99, tradução nossa).

Os grupos mais citados compreendem: grupos italianos (Máfia, 'Ndrangheta, Camorra); Yakuza e Boryokudan no Japão; Tríades chinesas; Cosa Nostra nos Estados Unidos; cartéis colombianos; Jamaican Posses; redes criminosas russas; sindicatos do oeste africano; clãs turcos; elemen- 
tos iranianos e outros grupos étnicos, como as organizações paquistanesas, iugoslavas e polonesas; gangues organizadas (de motociclistas fora da lei, de presos); skinheads; e milícias.

\section{Máfia e Máfias}

Umberto Santino salienta que o termo Máfia, que inicialmente descrevia um fenômeno localizado (siciliano), é atualmente usado para nominar qualquer grupo criminoso organizado, constituindo-se em uma espécie de paradigma ou quadro de referência para organizações similares que se desenvolveram noutros países em data mais recente. (Santino, 2003, p. 82, tradução nossa)

Hoje o mercado criminal é complexo, pois as atividades criminosas estão mais articuladas e os grupos cresceram em quantidade. Por conseguinte, é enganoso sustentar que a Máfia ou qualquer outra organização criminosa tenha um monopólio no mundo do crime. Não há uma monarquia (um número um) no crime organizado mundial, mas há muitas repúblicas que diversas vezes interagem e são protagonistas da divisão internacional do trabalho criminal. [...] A mistura entre o ilegal e o legal, o criminal e o institucional, está no coração da história do modelo da Máfia. Ele cresceu e se espaIhou independentemente da presença de mafiosos sicilianos ou siciliano-americanos. Não é que a Máfia invadiu o mundo, é o mundo que produziu mais e mais grupos e organizações do tipo Máfia (Santino, 2003, p. 82 e 84, tradução nossa).

A Máfia possui múltiplos aspectos: criminoso, político, econômico, cultural e social; e até 1982 não era considerada organização criminosa. Além de estrutura organizada e atividade criminal planejada, ela conta com uma capacidade extra: o exercício de poder através da intimidação sistemática, a omertà, espécie de lei de silêncio que funciona como uma garantia para os associados. Conforme Santino, ao lado da burguesia da 
Máfia existem os níveis mais pobres e marginalizados, para os quais a atividade criminosa oferece a possiblidade de mobilidade social. É difícil determinar o número, mas estima-se que existam centenas de milhares de pessoas envolvidas em atividades mafiosas na Sicília.

O autor cita organizações similares à Máfia espalhadas pelo mundo: Cosa Nostra (USA), Yakuza, Tríades chinesas, Cartéis latino-americanos, Máfia russa, Máfia nigeriana. Neste sentido, a atual divisão internacional do trabalho criminal (Santino, 2003, p. 83) torna o fenômeno do crime organizado mais complexo do que o paradigma representado pela Máfia siciliana.

\section{Medidas de enfrentamento e perspectivas futuras}

Os capítulos que tratam das experiências nacionais trazem, ainda, uma síntese das estratégias adotadas pelos governos para enfrentar o crime organizado, bem como as necessidades para a ampliação e o sucesso das intervenções. Ao lado da investigação e prisão dos membros, outra medida bastante reportada é o confisco dos bens e proventos ilícitos adquiridos pelas quadrilhas. Também estão sendo tomadas iniciativas para proteger testemunhas e colaboradores da justiça criminal.

Uma experiência interessante é a da África do Sul, comentada pelo chefe de polícia C. Venter (2003, p. 379-391). Lá são adotadas estratégias de curto, médio e longo prazo. Há uma estratégia nacional de prevenção do crime que entrelaça diversos departamentos e atividades, produzindo uma sensação de onipresença da polícia que diminui as probabilidades de cometimento de crimes. Ademais, existem os comitês de vigilância comunitária (neighborhood watch committees), bem como programas de educação pública.

A polícia sul-africana está reorganizando estruturas e atividades dentro dos princípios e objetivos da polícia comunitária, a qual promove a parceria com a comunidade e grupos de interesse a fim de lidar com os problemas 
criminais. Naquele país existem unidades especiais de repressão ao crime organizado, é realizado planejamento através de hotspots e hotlines, e estimulada a sinergia entre os grupos de investigação e registro/documentação.

Além disso, a África do Sul orienta-se por uma abordagem mais racional e integrada, tendo em vista aumentar a efetividade dos departamentos do sistema de justiça criminal, planejar e implementar estratégias contra o crime através de parcerias entre departamentos, agências policiais e atores externos. O plano de polícia de 1996, por exemplo, foi debatido publicamente e formulado de forma participativa. Após terem sido estabelecidas as prioridades, iniciou-se um processo para determinar as responsabilidades em nível nacional e provincial, que foi amparado por um abrangente plano de gerenciamento de cada prioridade (contendo objetivos, prioridades, atores envolvidos, atribuições, recursos necessários e indicadores de desempenho). Igualmente, há um esforço para se avaliar os resultados de cada estratégia, provendo accountability e transparência às agências do sistema de justiça criminal.

Dentre as necessidades repertoriadas nas experiências nacionais de enfrentamento do crime organizado, destacam-se:

Melhorar as estruturas e o funcionamento das instituições da justiça criminal: melhorar o treinamento nas agências locais, criar databases integradas. Integração entre as agências, coordenação interprovincial e interdepartamental. Desenvolver unidades especializadas para lidar com as várias formas de crime organizado.

Alguns autores comentaram o reduzido acúmulo de conhecimento científico acerca da natureza, das características e do desenvolvimento da criminalidade organizada.

Não basta só o reforço da legislação criminal e processual, são necessárias ações preventivas mais efetivas, e com participação social.

A lei de execução penal não deve ficar restrita a limites jurisdicionais estritos, uma vez que os criminosos não se circunscrevem às fronteiras geográficas, nacionais ou internacionais. 
Maior cooperação internacional, com operações conjuntas e compartilhamento de inteligência, bem como abordagem integrada e concertação para reduzir as oportunidades criminais e eliminar as condições propícias, nacionais e internacionais. Harmonização de legislação criminal de cada país, a fim de privar os criminosos dos paraísos fiscais. Remoção dos impedimentos legais ao livre movimento dos agentes da lei, simplificação de procedimentos, estabelecimento de estruturas regionais operativas e consultivas, bem como de escritórios para a coleta, armazenamento e difusão de informações.

Campanhas públicas contra o abuso de drogas e o tráfico de entorpecentes, através dos meios de comunicação e em escolas.

Investigar, criminalizar e punir a lavagem de dinheiro, embora ainda não existam medidas eficazes para fazê-lo. Os representantes dos países reclamaram da inexistência ou inadequação das leis contra a lavagem de dinheiro

Como muitos países não possuem recursos suficientes para a confrontação direta, pesquisadores colombianos propuseram a adoção de uma estratégia indireta, que priorize os fatores morais das sociedades.

Permanece a necessidade de encorajar todos os países a trabalhar juntos e planejar energicamente políticas e estratégias dirigidas aos traficantes de drogas e às companhias participantes da lavagem de dinheiro dos cartéis de droga. Eles também necessitam cooperar a fim de fortalecer os valores morais e éticos na sociedade, em termos de redução da cultura de consumo e do apoio dos meios de comunicação social, além de concentrar-se no amplo sistema de abastecimento e demanda que promove o tráfico de drogas (Rivera; Quadro; Botto, 2003, p. 316, tradução nossa).

No final do livro, Jay Albanese destaca cinco desafios primordiais para a Justiça Criminal responder ao avanço do crime organizado: a sua internacionalização, o problema da imigração, a corrupção policial, a necessidade de apoio legal e de imaginação, e inteligência na investigação 
e punição (como, por exemplo, o confisco dos ativos estrangeiros das organizações criminosas). Além dos esforços mais imediatos para evitar a infiltração do crime organizado nos negócios lícitos e reduzir a violência, são urgentes estratégias de prevenção de longo prazo, que ultrapassem o âmbito da justiça criminal.

Ainda na conclusão, Albanese (2003, p. 450) expõe o seu "modelo para avaliar o risco de crime organizado" em determinado espaço social, que inclui quatro níveis: a) fatores de oportunidade (pobreza do local, baixo nível de regulação do mercado pelo governo, baixa efetividade da justiça criminal, demanda pública pelo produto ou serviço ilícito, criação de mercado de novos produtos e serviços via mudança social ou tecnológica); b) ambiente criminal (pré-existência, ou não, de criminosos e de mercado para os produtos e serviços ilícitos; pré-existência, ou não, de grupos criminosos); c) habilidades especiais ou acesso necessário para realizar atividade (existência, ou não, de habilidades técnicas ou linguísticas, conexões com outros criminosos ou grupos, oportunidade especial de acesso); d) previsão de atividade de crime organizado (estimativa específica para cada produto ou serviço; estimativa de prejuízo ou dano).

Conclui-se que, embora não aprofunde teoricamente o conceito de crime organizado, o livro analisado fornece um panorama geral das categorizações existentes sobre este fenômeno social e, ao mesmo tempo, apresenta um mapeamento abrangente (contemplando seis continentes e dezenove países) das suas características, atividades e tendências nacionais, bem como das medidas adotadas em cada país para lidar com a criminalidade organizada.

Letícia Maria Schabbach. Doutora em Sociologia pela Universidade Federal do Rio Grande do Sul. Professora adjunta do Departamento de Sociologia da UFRGS. leticiams65@gmail.com 


\section{Referências}

ALBANESE, J. K. Conclusion: challenges for the Future. In: ALBANESE, J. S.; DAS, D. K.; VERMA, A. Organized Crime: World Perspectives. New Jersey: Prentice Hall, 2003, p. 438-459.

ALBANESE, J. K.; DAS, D. K. Introduction: A framework for understanding. In: ALBANESE, J. S.; DAS, D. K.; VERMA, A. Organized Crime: World Perspectives. New Jersey: Prentice Hall, 2003. p. 1-17.

ALBANESE, J. S.; DAS, D. K.; VERMA, A. Organized Crime: World Perspectives. New Jersey: Prentice Hall, 2003. 482 p.

ESTUDOS AVANÇADOS. Dossiê Crime Organizado. São Paulo, v. 21, n. 61, p. 77-97, 2007.

HEIJDEN, O. Organized Crime: a perspective from the Netherlands In: ALBANESE, J. S.; DAS, D. K.; VERMA, A. Organized Crime: World Perspectives. New Jersey: Prentice Hall, 2003. Cap. 4, p. 101-126.

KOENIG, D. J. Organized Crime: a canadian perspective. In: ALBANESE, J. S.; DAS, D. K.; VERMA, A. Organized Crime: World Perspectives. New Jersey: Prentice Hall, 2003. Cap. 2, p. 46-77.

PLYWACZEWSKI, E. W. Organized crime: a perspective from Poland and Eastern Europe. In: ALBANESE, J. S.; DAS, D. K.; VERMA, A. Organized Crime: World Perspectives. New Jersey: Prentice Hall, 2003. Cap. 5, p. 127-145.

RIVERA, L. J. R.; QUADRO, J. C.; BOTTO, J. M. T. Organized Crime: a perspective from Colombia. In: Organized crime: a perspective from Poland and Eastern Europe. In: ALBANESE, J. S.; DAS, D. K.; VERMA, A. Organized Crime: World Perspectives. New Jersey: Prentice Hall, 2003. Cap. 13, p. 301-316.

SANTINO, U. Mafia and Mafia-type organizations in Italy. In: ALBANESE, J. S.; DAS, D. K.; VERMA, A. Organized Crime: World Perspectives. New Jersey: Prentice Hall, 2003. Cap. 3, p. 82-100.

VENTER, C.J.D. Organized Crime: a perspective from South Africa. In: ALBANESE, J. S.; DAS, D. K.; VERMA, A. Organized Crime: World Perspectives. New Jersey: Prentice Hall, 2003. Cap. 17, p. 379-391.

VERMA, A.; TIWARI, R. K. Organized crime: a perspective from India. In: ALBANESE, J. S.; DAS, D. K.; VERMA, A. Organized Crime: World Perspectives. New Jersey: Prentice Hall, 2003. Cap. 10, p. 240-266.

Recebido em: 30/07/2012

Aceite final: 10/10/2012 